\title{
Left Ventricular Outflow Tract Obstruction after Ross-Konno Operation
}

\author{
Cenap Zeybek $^{1}$, Mustafa Kemal Avşar ${ }^{2 *}$, Özgür Yildirim³ ${ }^{3}$, Mehmet Salih Bilal $^{3}$ \\ ${ }^{1}$ Department of Pediatric Cardiology, Biruni University Hospital, Istanbul, Turkey \\ ${ }^{2}$ Department of Cardiovascular Surgery, Medicana International Istanbul Hospital and Istanbul Gelisim University Medical \\ Sciences Institute, Istanbul, Turkey \\ ${ }^{3}$ Department of Cardiovascular Surgery, Medicana International Istanbul Hospital, Istanbul, Turkey \\ Email: *mustafakemalavsar@hotmail.com
}

How to cite this paper: Zeybek, C., Avşar, M.K., Yildirim, Ö. and Bilal, M.S. (2017) Left Ventricular Outflow Tract Obstruction after Ross-Konno Operation. Open Access Library Journal, 4: e3644. https://doi.org/10.4236/oalib.1103644

Received: May 2, 2017

Accepted: June 25, 2017

Published: June 30, 2017

Copyright $\odot 2017$ by authors and Open Access Library Inc.

This work is licensed under the Creative Commons Attribution International License (CC BY 4.0).

http://creativecommons.org/licenses/by/4.0/

(c) (i) Open Access

\begin{abstract}
INTRODUCTION: SAM (systolic anterior motion) is defined as the dynamic motion of the anterior mitral valve leaflet to the left ventricular outflow tract (LVOT) during systole. In this study, we present a case which we encountered with significant left ventricular outflow tract obstruction (LVOTO) related to SAM and developed after Ross-Konno operation. METHOD: A 4-month, 6.2 $\mathrm{kg}$ girl underwent balloon valvuloplasty due to bicuspid aortic stenosis when she was one-month. Ross-Konno operation was performed on the patient due to residual aortic stenosis (peak gradient of $140 \mathrm{~mm} \mathrm{Hg}$ ) and severe aortic regurgitation. Intraoperative echocardiography (ECHO) showed a peak gradient of $25 \mathrm{mmHg}$ between the LV-Aorta. RESULTS: In the ICU at postoperative 3. hour, when tachycardia began with the patient's hemodynamic deterioration, SAM in ECHO and concomitant LVOTO (Peak grad: $140 \mathrm{mmHg}$ ) and 2nd degree MY was identified. Pulmonary edema was observed along with a decrease in oxygen saturation. The treatment initiated for removing the patient from hyperdynamic state and reducing the volume deficit. Sedation and analgesia were increased. The low-dose dobutamine was stopped. Tachycardia was attempted to take control with beta-blockers. The same treatment was continued on day 2, but the frequency of patient's tachycardia has not been reduced despite high doses of beta blockers. Heart rate was controlled by Amiodarone. On day 4, mitral regurgitation was slightly decreased while the LV-Aorta gradient was measured between $50-60 \mathrm{mmHg}$. On day 5, SAM has diminished greatly $(20 \mathrm{mmHg})$. The patient was extubated 6 th day and was discharged on the 12th day without any problem. One year after, LVOT gradient was not detected in the ECHO. DISCUSSION: In adult patients, although a variety of surgical procedures for the removal of SAM had been reported, no experience in infants exists in the literature on these techniques. Despite intensive medical treatment, it may take longer than expected. We
\end{abstract}


think that also the decline of existing preoperative LV hypertrophy in this period contributes.

\section{Subject Areas}

Cardiology, Pediatrics, Surgery \& Surgical Specialties

\section{Keywords}

Systolic Anterior Motion Of Mitral Valve, Ross-Conno Operatio, Left Ventricular Outflow Tract Obstruction

\section{Introduction}

SAM (systolic anterior motion) is defined as the dynamic motion of the anterior mitral valve leaflet to the left ventricular outflow tract (LVOT) during systole and was first described about 40 years ago by Termini et al. [1]. Systolic anterior motion (SAM) related to left ventricular outflow tract obstruction (LVOTO) can vary from causing clinically silent disease to severe LVOTO in a diversity [2]. Although the mitral valve's SAM usually is seen in asymmetric septal type of hypertrophic cardiomyopathy, but also can be seen in hypertensive heart disease, after the aortic and mitral valve surgery in diabetic people, in acute myocardial infarction, and even in asymptomatic patients during dobutamine pharmacological stress test and is a condition that causes the dynamic LVOTO [3]. A variety of surgical procedures have been reported in adult patients for the removal of SAM, but no experience in infants exists in the literature on these techniques. In this study, we wanted to present a patient which we encountered with significant left ventricular outflow tract obstruction (LVOTO) related to SAM after Ross-Konno operation and how we overcame this period with no problems and the strategy we used.

\section{Case Report}

A 4-month, $6.2 \mathrm{~kg}$ girl underwent balloon valvuloplasty due to congenital aortic stenosis when she was one-month. Ross-Konno operation (with $16 \mathrm{~mm}$ Contegra) performed on the patient due to bicuspid aortic valve, previous balloon valvuloplasty + residual aortic stenosis + significant aortic regurgitation (AR), LVOTO (the mean gradient of $90 \mathrm{mmHg}$ between left ventricle (LV)-aorta), 25 mm HG peak gradient was present in the preoperative made transesophagealechocardiography (TEE) between LV-Aorta, there was no neoaortic failure, any other problems was not available. In the postoperative 3 hours, while deteriorating hemodynamics in intensive care when tachycardia began, SAM in ECHO and concomitant LVOTO (Peak grad: $140 \mathrm{mmHg}$ ) and 2nd degree mitral valve regurgitation (MR) was identified, no neoaortic failure was observed and the pulmonary xenograft functioned (Figure 1 and Figure 2).

The medical follow-up was decided for removing from left ventricular hyper- 


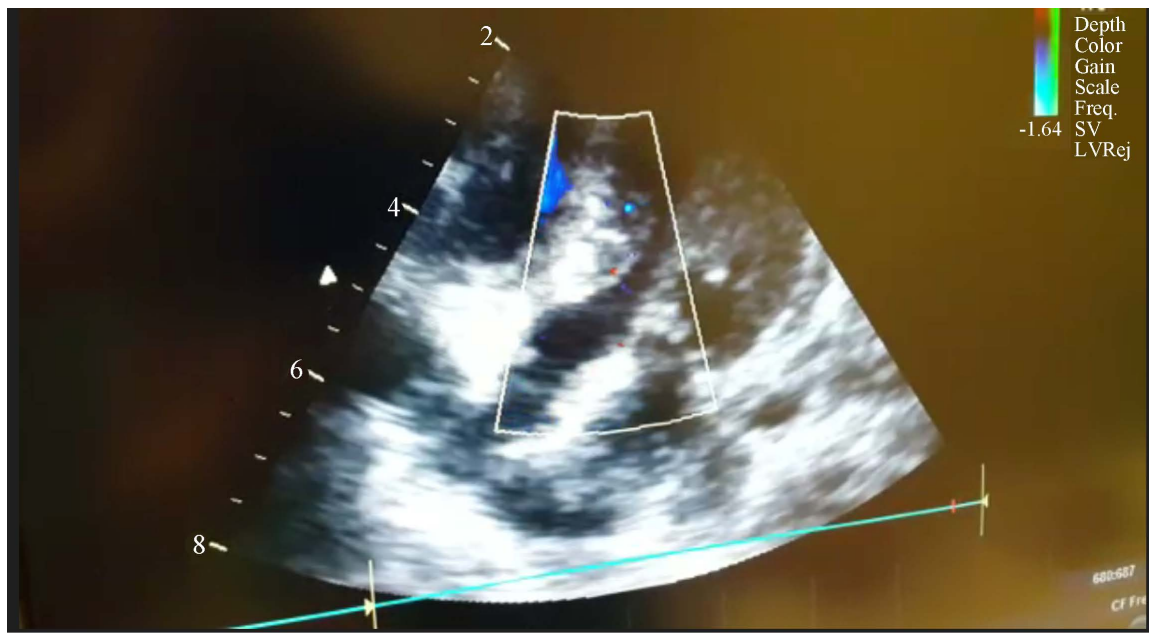

Figure 1. Echocardiography findings in postoperative 3th hour.

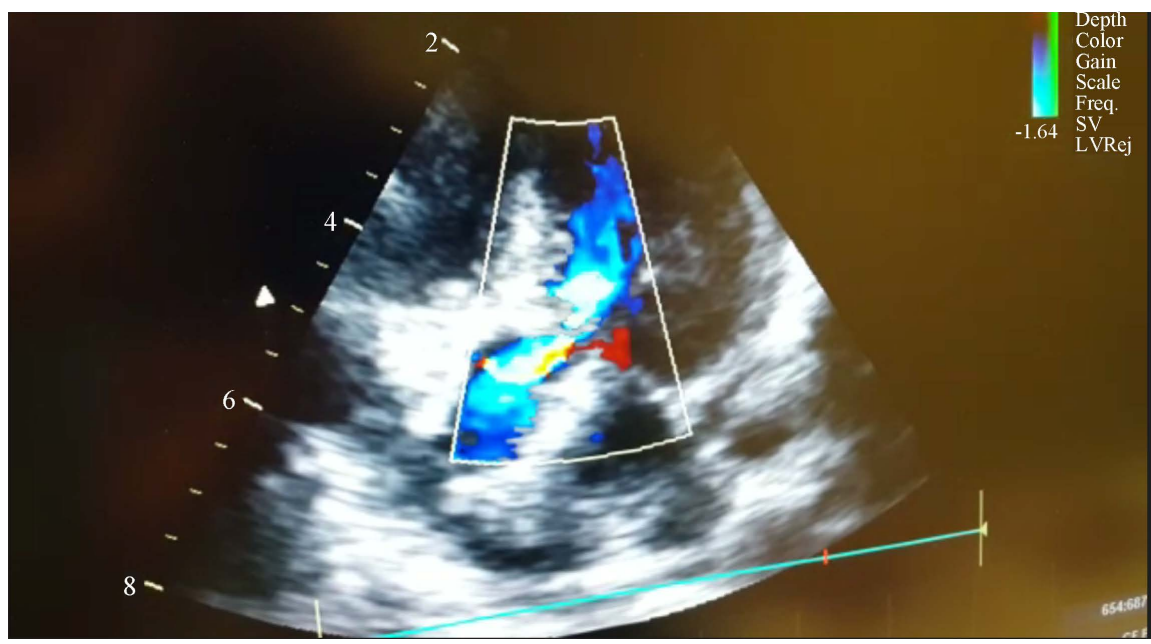

Figure 2. Color doppler echocardiography findings in postoperative 3th hour.

dynamia, the treatment initiated until reducing the volume deficit and the ventricle was dilated until reduction of gradient. The patient's sedation and analgesia dose was increased, dobutamine perfusion was stopped, the volume deficit was reduced with liquid application, the patient's tachycardia tried to slow with digoxin and with the $\beta$-blocker medications, the patient's pulse rate of $200 / \mathrm{min}$ declined to $170 / \mathrm{min}$. The findings in the 1 st postoperative day ECHO was the same as previous one. $\beta$ blocker application and liquid loading were continued in postoperative 2 day to but the patient's tachycardia could not slowed. Postoperative 3 th day, amiodarone perfusion was started and the patient's pulse rate could be reduced to $130 / \mathrm{min}$, hemodynamic stabilization was achieved. ECHO made in the first 4 days postoperatively, while LV-Aorta gradient was reduced to between $50-60 \mathrm{mmHg}$, mitral regurgitation decreased and $1-2$. degree MR was present. While Amiorodone perfusion continued in postoperative 5. day, LVOT gradient related to SAM in her ECHO was observed to decrease up to $20 \mathrm{mmHg}$. The patient was extubated postoperative 6. day and in ECHO after the extubation maximum LV-aorta gradient was seen as no more than $20 \mathrm{~mm} \mathrm{Hg}$. The pa- 
tient was discharged in postoperative 12. day without any problem. One year after, LVOT gradient was not detected in the ECHO.

\section{Discussion}

The functions of the mitral valve depends on leaflets of the mitral valve, the sub-valvular apparatus of papillary muscles, the annulus, chorda tendinea and also depends on the the global left ventricular structure and contractility. Any changes in these functional units can contribute to SAM [2]. The mitral valve of SAM may appear in a life-threatening case of hypertrophic cardiomyopathy by causing dynamic LVOT obstruction, after cardiac surgery including especially mitral valve surgery and after a variety of medical and metabolic conditions [2]. Although it is less common, it can be seen in infants with congenital heart disease and also after congenital heart surgery [4] [5]. When we examined the literature, we couldn't identify any case of LVOTO related to SAM after RossKonno like our case. Diagnosis can be made with a detailed echocardiography and magnetic resonance imaging. The first option in the treatment is medical treatment and the last option is surgery. The studies have showed that in LVOTO gradient related to SAM liquid loading, the $\beta$-adrenoceptor blockade, phenylephrine were adequate for the treatment. In the treatment protocol of 174 patients which was applied by Sam Brown and et al., it was indicated that the majority of patients improved and only 4 patients required surgical intervention. Furthermore, in this study, SAM insisted in the long-term follow-up of $17 \mathrm{pa-}$ tients, the best option is medical treatment in mild SAM and surgery can be considered in a case of severe LVOTO related to SAM [6]. In our case, while postoperative 3th hour hemodynamics deteriorated with entering into pulmonary edema plane, when we faced with about $140 \mathrm{~mm} \mathrm{Hg}$ gradient of LVOTO related to SAM, we initiated the fluid replacement therapy with dobutamine termination and we started thinking about surgical options. We have decided to wait for surgery when we sustained relatively clinical and echocardiographic relief with $\beta$ block and fluid replacement. The amiodarone perfusion was initiated in order to reduce the speed and we have reached the targeted heart rate of 120 $130 / \mathrm{min}$. We provided the dilation of the left ventricle with sufficient volume treatment. With all these measures, LVOTO reduced to $20 \mathrm{~mm}$ hg level after in the postoperative 6 day ECHO, the patient extubated and we were able to discharge without any problem. In postoperative 1 year ECHO, SAM-related obstruction disappeared, there was $5-10 \mathrm{mmHg}$ gradient between LV-aorta and there was no evidence of a problem in the 1-year follow-up of the patient. Hypovolemia and the left ventricle hyperdynamical were considered to be as possible causes of SAM. We believe that this depends on the elimination of the LVOTO related to Ross-Konno, there was yet no dilation on the left ventricle and its geometry under hyperdynamic period and under hypovolemia.

\section{Conclusion}

After ROSS-Konno operation, dynamic LVOTO developed with related to mitral 
valve's SAM is a rare condition. Although dynamic LVOTO related to SAM remains benign, it is an important condition that can cause refractory cardiogenic shock and even can lead to death. After Ross Konno operation depending on the removal of LVOTO obstruction, after the hyperdynamic period of left ventricle with reduction of the left ventricle dilatation and contractions, aggressive fluid loading and amiodarone, $\beta$-blocker drugs, with the use of drugs like calcium channel blockers that decrease heart rate and with discontinuation of the drugs as dobutamine that increases cardiac contraction and heart rate, we believe that it is a pathology that can be resolved and even disappear within days. Surgical treatment is a last resort. Dynamic LVOTO related to SAM must be diagnosed early and it should be noted that it can be serious and even a lethal case.

\section{References}

[1] Termini, B.A., Jackson, P.A. and Williams, C.D. (1977) Systolic Anterior Motion of the Mitral Valve Following Annuloplasty. Journal of Vascular Surgery, 11, 55-60. https://doi.org/10.1177/153857447701100203

[2] Ibrahim, M., Rao, C., Ashrafian, H., Chaudhry, U., Darzi, A. and Athanasiou, T. (2012) Modern Management of Systolic Anterior Motion of the Mitral Valve. European Journal of Cardio-Thoracic Surgery, 1-11. https://doi.org/10.1093/ejcts/ezr232

[3] Luckie, M. and Khattar, R.S. (2008) Systolic Anterior Motion of the Mitral ValveBeyond Hypertrophic Cardiomyopathy. Heart, 94, 1383-1385.

[4] Iwata, Y., Imai, Y., Shin'oka, T. and Kurosawa, H. (2008) Subaortic Stenosis Associated with Systolic Anterior Motion. Heart Vessels, 23, 436-439.

[5] Zurick III, A.O. and Menon, V. (2010) Dynamic Outflow Tract Obstruction in Congenitally Corrected Transposition of the Great Arteries. The International Journal of Cardiovascular Imaging, 26, 617-619. https://doi.org/10.1007/s10554-010-9588-1

[6] Brown, M.L., Abel, M.D., Click, R.L., Morford, R.G., Dearani, J.A., Sundt, T.M., et al. (2007) Systolic Anterior Motion after Mitral Valve Repair: Is Surgical Intervention Necessary? The Journal of Thoracic and Cardiovascular Surgery, 133, 136-143. https://doi.org/10.1016/j.jtcvs.2006.09.024

\section{Open Access Library}

Submit or recommend next manuscript to OALib Journal and we will provide best service for you:

- Publication frequency: Monthly

- 9 subject areas of science, technology and medicine

- Fair and rigorous peer-review system

- Fast publication process

- Article promotion in various social networking sites (LinkedIn, Facebook, Twitter, etc.)

- Maximum dissemination of your research work

Submit Your Paper Online: Click Here to Submit

Or Contact service@oalib.com 